\title{
PostCOVID-19 Syndrome - The New Pandemic
}

PostCOVID-19 syndrome or the long COVID has affected many who have recovered from the COVID-19. ${ }^{[1]}$ There has often been a longer struggle, after the initial recovery. ${ }^{[1]}$ PostCOVID-19 syndrome affects those who have recovered from even mild COVID-19. ${ }^{[1]}$ These are health issues that persist even 3 months after the onset of the initial infection. ${ }^{[1]}$ Symptoms such as fever, cough, breathlessness, myalgia, headache, loss of smell or taste, and fatigue even with slight exertion, neurological symptoms such as dizziness may occur as part of the postCOVID-19 syndrome. ${ }^{[1,2]}$ It has been reported that only $13 \%$ of the hospitalized individuals who have recovered from COVID-19, have not experienced any symptoms thereafter and $>50 \%$ continue to have up to three or more symptoms. ${ }^{[1,3]}$ The difference in symptomatology in the postCOVID-19 syndrome is that in contrast to the predominant pulmonary symptoms during the active COVID-19 infection, a myriad of atypical symptoms such as fatigue, diarrhea, palpitations, headache, ageusia, anosmia, and raised body temperature are seen. ${ }^{[1]}$ The similarity is that just such as COVID-19 illness, the postCOVID-19 syndrome is also a multisystem disorder. ${ }^{[4]}$

A study has reported that fatigue, breathlessness, and posttraumatic stress disorder (PTSD) were the most common symptoms among COVID-19 recovered individuals, not only among patients who were admitted to the intensive care unit (ICU) during the COVID-19 illness but also among ward patients as well. ${ }^{[5]}$ The study also noted memory problems, pain symptoms, and continence issues in $10 \%-15 \%$ of people. ${ }^{[5]}$

Fatigue, which is especially common as the long COVID symptom, incorporates a spectrum of health issues such as shortness of breath, cognitive dysfunction, and psychological distress as well. ${ }^{[5,6]}$ The cause of fatigue has often been attributed to anemia, hypothyroidism, and Vitamin D deficiency, which should not be missed by the treating physician. ${ }^{[5,6]}$

Breathlessness was more common in those who required respiratory support prior, during illness, and was obese..$^{[5]}$ PTSD due to psychological trauma was more common among females, those with ICU admission and among healthcare workers. ${ }^{[5]}$ The experience of seeing others suffer as well as one's own suffering, being isolated from near and dear ones, may lead to PTSD.

It is not exactly known why people continue to experience symptoms as part of postCOVID-19 syndrome, but weak antibody response, relapse, immune reactions, inflammatory reactions, and deconditioning have been described as contributory factors. ${ }^{[7-9]}$ These inflammatory reactions may present even as vesicular, maculopapular, or vesicular skin rashes in few patients, known as "COVID toe."[9,10]
The management of the symptoms of the postCOVID-19 syndrome has been categorized in two sections self-management and medical management. ${ }^{[9]}$ Self-management includes monitoring of oxygen saturation by pulse oximetry, nutritious diet and adequate sleep, quitting smoking and alcohol, and gradually building up exercise tolerance wherever feasible. ${ }^{[9]}$ Medical management involves symptomatic treatment with antipyretics, antibiotics for secondary bacterial infections and respiratory, cardiology, neurology evaluation, and follow-up as required. ${ }^{[9]}$

There is an urgent need for the setting up of comprehensive postCOVID-19 care clinics as well, and the well-structured RECOVERY (Comprehensive PostCOVID Centre at Yale) program is a testimony to that. ${ }^{[1]}$ The essence of the RECOVERY program was aimed to ensure a comprehensive evaluation of postCOVID-19 issues including rehabilitation. ${ }^{[11]}$ The postCOVID center at Yale consists of four components-referral pathway, initial assessment and evaluation, subsequent care, and then disposition. Apart from the conventional assessment for causality of symptoms with pulmonary and cardiac imaging, it also has mental health screening facilities for postCOVID-19 patients. ${ }^{[11]}$ A postCOVID-19 care clinic model treating patients with postCOVID-19 syndrome should address the following aspects - anticipate and identify the postCOVID-19 complications first, assess the extent of pulmonary abnormalities persisting, provide medical management to the symptomatic issues to reduce distress, evaluate extrapulmonary sequelae, provide support for psychological as well as cognitive dysfunction and assist in physical rehabilitation. ${ }^{[11]}$ New onset of venous thromboembolism must be looked for when breathlessness is not resolving with conventional medical management. ${ }^{[12]}$

Another important aspect of these clinics is the provision of palliative care in cases that are deemed suitable. ${ }^{[12]}$ Such well-structured postCOVID care clinics will be a boon for many, and in India with a large population having a propensity to suffer from the postCOVID-19 syndrome, it is also the need of the hour. It will be the perfect example of quintessential healthcare, where we not only provide treatment and vaccines for COVID-19 but can also provide integrated care to our people suffering from the postCOVID-19 syndrome.

With the resurgence of the second wave of COVID-19 in India despite the advent of vaccines, even more, patients will require care for this new pandemic "postCOVID-19 syndrome." In such a situation, these post COVID care clinics will be beneficial to numerous patients, many of whom will be our own health care workers who had been affected during the line of duty. 


\section{Souvik Chaudhuri}

Department of Critical Care, Kasturba Medical College, Manipal Academy of Higher Education, Manipal, Karnataka, India

Address for correspondence: Dr. Souvik Chaudhuri, Department of Critical Care, Kasturba Medical College, Manipal Academy of Higher Education, Manipal, Karnataka, India. E-mail: souvikchaudhuri1207@gmail.com

\section{REFERENCES}

1. Goërtz YM, Van Herck M, Delbressine JM, Vaes AW, Meys R, Machado FV, et al. Persistent symptoms 3 months after a SARS-CoV-2 infection: The post-COVID-19 syndrome? ERJ Open Research 2020;6 (4) $00542-2020$.

2. Li LQ, Huang T, Wang YQ, Wang ZP, Liang Y, Huang TB, et al. COVID-19 patients' clinical characteristics, discharge rate, and fatality rate of meta-analysis. J Med Virol 2020;92:577-83.

3. Carfì A, Bernabei R, Landi F, Gemelli Against COVID-19 Post-Acute Care Study Group. Persistent symptoms in patients after acute COVID-19. JAMA 2020;324:603-5.

4. Balachandar V, Mahalaxmi I, Subramaniam M, Kaavya J, Senthil Kumar N, Laldinmawii G, et al. Follow-up studies in COVID-19 recovered patients-Is it mandatory? Sci Total Environ 2020;729:139021.

5. Halpin SJ, McIvor C, Whyatt G, Adams A, Harvey O, McLean L, et al. Postdischarge symptoms and rehabilitation needs in survivors of COVID-19 infection: A cross-sectional evaluation. J Med Virol 2021;93:1013-22.

6. Chen M, Zhou $\mathrm{W}, \mathrm{Xu}$ W. Thyroid function analysis in 50 patients with COVID-19: A retrospective study. Thyroid 2021;31:8-11.

7. Wu F, Wang A, Liu M, Chen J, Xia S, Ling Y, et al. Neutralizing antibody responses to SARS-CoV-2 in a COVID-19 recovered patient cohort and their implications. medRxiv 2020.03.30.20047365. [doi: 03.30.200473652020].
8. Lan L, Xu D, Ye G, Xia C, Wang S, Li Y, et al. Positive RT-PCR test results in patients recovered from COVID-19. JAMA 2020;323:1502-3.

9. Greenhalgh T, Knight M, A'Court C, Buxton M, Husain L. Management of post-acute covid-19 in primary care. BMJ 2020;370:m3026.

10. Gemelli Against COVID-19 Post-Acute Care Study Group. Post-COVID-19 global health strategies: The need for an interdisciplinary approach. Aging Clin Exp Res 2020;32:1613-20.

11. Lutchmansingh DD, Knauert MP, Antin-Ozerkis DE, Chupp G, Cohn L, Dela Cruz CS, et al. Clinic blueprint for post-coronavirus disease 2019 RECOVERY: Learning from the past, looking to the future. Chest 2021;159:949-58

12. BTS Guidance on Respiratory Follow Up of Patients with a ClinicoRadiological Diagnosis of COVID-19 Pneumonia v1.2 11/5/2020.

This is an open access journal, and articles are distributed under the terms of the Creative Commons Attribution-NonCommercial-ShareAlike 4.0 License, which allows others to remix tweak, and build upon the work non-commercially, as long as appropriate credit is given and the new creations are licensed under the identical terms.

\begin{tabular}{|l|l|}
\hline \multicolumn{3}{|c|}{ Access this article online } \\
\hline Quick Response Code: & Website: \\
\hline & www.ijrc.in \\
\hline & \\
\hline
\end{tabular}

How to cite this article: Chaudhuri S. Post COVID-19 syndrome - The new pandemic. Indian J Respir Care 2021;10:169-70.

Received: $21-04-2021$

Published: 14-06-2021 